\title{
EL COMERCIO INTERNACIONAL ENTRE ESPACIOS ABIERTOS.
}

En la teoría del comercio internacional estamos tratando problemas nuevos con herramientas todavīa tradicionales. Problemas nuevos que surgen de la complejidad creciente de las relaciones comerciales entre países y unas herramientas que fueron concebidas para un comercio internacional bastante más simple del que tenemos actualmente. Veamos algunos casos.

La apertura al exterior de una economía se suele medir a través del cociente entre magnitudes que reflejan el volumen del comercio exterior y el volumen del PIB. Este cociente, conforme va avanzando el tiempo y se incrementa el nivel de complejidad en el comercio internacional, se va desdibujando y perdiendo contenido explicativo. Dos cuestiones. La primera tiene que ver con la composición sectorial de la producción. El comercio internacional recoge bienes básicamente de la agricultura y de la industria (los comerciables) mientras que el denominador abarca el conjunto del PIB. Con el paso del tiempo, y en presencia de crecimiento económico, al irse incrementando la aportación del sector servicios al PIB, el coeficiente de apertura tiende a disminuir. Un problema de este tipo es el que se le plantea a P. Krugman cuando llega a afirmar que la apertura al exterior durante la primera globalizaciōn (desde finales del XIX hasta 1914) era todavía mayor que la que tenemos actualmente. La soluciōn a esta aparente paradoja está en la aportación de los servicios que, básicamente, no entran en la balanza comercial. La forma de enmendar esta anomalía sería la de incorporar el comercio de servicios en el numerador de la expresiōn o, al revés, excluir el sector servicios del denominador. En cualquier caso, la tarea no es sencilla. Además, debemos considerar que la balanza comercial incluye también un componente creciente de bienes del sector servicios: planos, música, películas, software, etc.

Una segunda cuestión es ya más de fondo. El denominador del coeficiente de apertura recoge solamente los bienes finales, mientras el numerador incorpora los bienes finales y los intermedios, estos últimos con un peso en el conjunto cada vez más relevante, debido a la especialización vertical y el offshoring, que hace que los bienes intermedios sean un componente cada vez mayor del comercio internacional como un todo. Esta anomalía tendría una 
tendencia a incrementar la tasa de apertura, probablemente, compensando parcialmente la tendencia en sentido contrario del crecimiento de los servicios en el PIB. Bajo el punto de vista contable, el problema se complica todavía más al considerar que las exportaciones de intermedios son productos finales bajo el punto de vista del PIB. Una posible solución a este problema vendría de la mano de no considerar en el denominador el PIB sino el Valor Total de la Producciōn, es decir, la suma del PIB y de la producciōn de intermedios. La informaciōn sobre el Valor Total de la Producción prácticamente dejó de recogerse en la Contabilidad Nacional desde hace ya tiempo. Otra soluciōn, no mucho más fácil a nivel metodológico, sería eliminar del numerador los productos intermedios dejando únicamente los productos finales. Ahora bien, esto habría que hacerlo diferenciando entre importaciones y exportaciones. Tampoco ésta es tarea sencilla bajo el punto de vista contable. Además, y como un denominador común a todo lo anterior, la diferenciaciōn entre bienes comerciables y no comerciables tiene una frontera cada vez más difusa.

El concepto de tasa de cobertura se sigue utilizando con frecuencia y es cada vez más un concepto que deja de responder a su diseño original. No recoge la elevada complejidad de las actividades comerciales entre espacios abiertos. El segmento de las importaciones que se financia con las exportaciones parte de la hipótesis de que tanto unas como otras son producidas integramente en el país y, el saldo, revela la posición acreedora (deudora) de ese país frente al exterior. Hoy esto ya no es así. Las exportaciones de cualquier país desarrollado contienen importaciones previas que pueden llegar a ser un segmento muy relevante en ese flujo. Y con las importaciones lo mismo: el contenido en exportaciones previas de la corriente importadora no es desdeñable. Y esta situaciōn es todavía más acentuada si bajamos a niveles más desagregados. En capítulos muy importantes de la Nomenclatura Combinada (por ejemplo, el capítulo 87, Material de transporte terrestre excepto el ferroviario) este fenómeno es muy visible. Tampoco se soluciona el problema bajando a niveles más desagregados. Los flujos dentro de cada posición a ocho dígitos son intensos en las dos direcciones.

La dificultad reside en calcular los flujos netos. Una definición más correcta de la tasa de cobertura, y del propio saldo comercial, sería el cociente entre las exportaciones netas (deducidas las importaciones previas incluidas en esas exportaciones) sobre las importaciones netas. Este cociente --definido asī-- recogería una mayor parte de la complejidad existente en las relaciones comerciales de un país, que el mismo cociente definido de forma tradicional. La dificultad reside en extraer de las exportaciones, por ejemplo, las importaciones previas. ¿qué parte de las exportaciones de automóviles españolas son importaciones previas incorporadas a esas exportaciones? Este porcentaje variará de una empresa a otra y, dentro de una misma empresa, variará de un producto a otro. Y esto suponiendo que la empresa en cuestión no diferencia entre el mercado nacional y el exterior: que el producto es el mismo en los dos mercados. Y así sucesivamente para las 10.000 posiciones de la Nomenclatura Combinada. Inabordable. 
En esta última década se ha tratado de solucionar este problema a través de la contabilizaciōn del valor añadido. En definitiva, una economía dada estaría exportando e importando valor añadido a unos intermedios que pueden ser, o no, de producción nacional. La idea es muy interesante, pero limita con la informaciōn disponible suministrada por las aduanas nacionales. Aunque hay algunas bases de datos que recogen la información sobre el valor añadido, las aduanas, prácticamente en todo el mundo, contabilizan exclusivamente el valor estadístico y el valor factura, valores que discrepan entre sí por cuestiones fiscales (IVA, por ejemplo) y algunos costes de transporte. Ninguna información sobre el valor añadido en la información aduanera de los países sujetos al Sistema Armonizado, es decir, prácticamente todos.

Otra forma de abordar esta cuestión es a través de unas tablas Input Output con un nivel de desagregación aceptable. En principio no tendríamos problema. Los límites de esta metodología no serían de informaciōn, sino de periodicidad. Las tablas Input-Output aparecen con años de retraso y de forma intermitente y variable. Además, en algunos casos, las agregaciones sectoriales son distintas, lo que no permite hacer estudios comparados de ámbito internacional, quedándose la mayoría de las veces, en ámbitos nacionales exclusivos de unos pocos paîses desarrollados.

Debemos tener en cuenta que estas limitaciones del concepto de tasa de cobertura no se quedan solamente ahí. Son generalizables a coeficientes tan conocidos y utilizados como los Bela Balassa, Grubel y Lloyd, etc.

La cuestión de las exportaciones previas que vienen contenidas en las importaciones nos lleva a una cuestión fundamental y que tiene que ver con la propia naturaleza del comercio internacional. Gran parte de este último ni es comercio ni es internacional. La relación comercial implica que los derechos de propiedad de un bien (en este caso comerciable) pasa de un residente a un no residente en el caso de las exportaciones y, al contrario, en el caso contrario. Precisamente por esto el avituallamiento a buques y naves de pabellón extranjero en puertos nacionales se contabilizan como exportaciones (habitualmente en el Cap. 99 de la Nomenclatura Combinada). La complejidad reside en que una parte importante del comercio internacional se realiza entre residentes y no residentes que lo son de iure (pero no de facto) ya que los dos extremos de la relación pertenecen a la misma empresa multinacional que tiene establecidas cadenas de producción globales. Este tipo de comercio, denominado habitualmente intrafirma, genera un nivel de complejidad muy importante en el estudio del comercio internacional. Distorsiona los precios (generando precios sombra), en gran medida es el responsable del comercio entre productos similares (el denominado comercio intraindustrial) y, una cuestión que resulta fundamental, arroja dudas sobre la naturaleza misma del objeto de comercio, es decir, sobre el concepto de mercancía.

En sentido estricto, los productos intrafirma y asimilables están fuera del mercado y, en consecuencia, fuera del comercio. Los productos en curso de fabricaciōn (partes, piezas, componentes, accesorios, etc.) se pueden identifi- 
car fácilmente a través de la Clasificación por Grandes Categorías Económicas de Naciones Unidas (B.E.C. por sus siglas en inglés) y son un tipo de bienes de no mercado, esto es, que se transaccionan al margen del mercado. Dicho en otros términos ¿a quiénes les puede interesar miles de volantes de un modelo de automóvil muy concreto? Al fabricante. A nadie más. Lo relevante es que este tipo de comercio representa un porcentaje importante en el comercio internacional. En otros términos, una parte muy importante de lo que tenemos registrado como comercio internacional se realiza fuera del mercado mundial, en un sector paralelo de no mercado (eso sí, internacional). Este sector paralelo de no mercado produce bienes que están al margen de la oferta y de la demanda y los precios se determinan a priori. Oferta, demanda y determinación de precio coincide en el mismo agente.

Otro elemento básico en el comercio internacional, en el sentido más tradicional del concepto, es el hecho de que incorpora dos países distintos entre ellos y, aunque en la mayoría de las veces no se explicita, la existencia de una tasa de cambio que media en la transacción y unos aranceles cuya función es distorsionar los precios de las importaciones en favor de la producción autóctona en cada país. Esta particularidad no afecta a porcentajes cada vez más amplios del comercio internacional. Las tasas de cambio, o bien no existen (caso de la eurozona) o están dolarizadas (gran parte de américa latina) o sometidas a flotaciones sucias y auto controladas como puede ser el caso de China o Japón. En lo que se refiere a los aranceles, y en la práctica de lo que va de siglo, prácticamente no distorsionan el comercio. Aunque por posiciones del Sistema Armonizado existen picos importantes en algunos sectores de algunas economías, el arancel medio de USA o de la Uniōn Europea no llega a alcanzar el dos por ciento.

Las herramientas que tenemos para analizar el comercio internacional no son capaces de recoger la enorme complejidad de las relaciones productivas y comerciales que son inherentes a la globalización. Conforme ésta ha ido avanzando, el estado nación (moneda, aranceles, y una dotación factorial específica) se ha ido disolviendo y lo que hasta un momento era comercio internacional ha ido transformándose en un comercio interregional (entre espacios abiertos) que refleja la integración de los sistemas productivos nacionales como una parte (frecuentemente prescindible) de procesos productivos a escala global.

Julio G. Sequeiros Tizón 